\title{
La investigación narrativa como construcción social del conocimiento, una aproximación epistemológica y metodológica desde el enfoque cualitativo
}

\section{Narrative research as a social construction of knowledge, an epistemological and methodological approach from the qualitative methods.}

\author{
Johan Andrés Nieto Bravo ${ }^{1}$ \\ Mario Alejandro Angarita Mendoza ${ }^{2}$ \\ Juan David Muñoz Velázquez ${ }^{3}$ \\ Gustavo Alejandro Labrador Mancilla ${ }^{4}$
}

DOI: 10.29151/hojasyhablas.n17a4

\section{Resumen}

En la sociedad hay diferentes grupos poblacionales en espacios o condiciones de vida vulnerables, los cuales son invisibilizados y excluidos de la misma por las mitificaciones o prejuicios sociales. Por ello, se genera la necesidad de que estos recobren la voz negada y se les empodere en su capacidad de expresión, logrando resignificar su propia realidad y la que les circunda. En esa necesidad de re-significación de la experiencia humana, es preciso que más allá de identificar o describir las formas de vida de cada uno de los individuos, puedan ser ellos mismos quienes muestren al mundo su propia humanidad. La interpretación y comprensión de su ser-en-el-mundo es por ende el objetivo de la presente investigación, y por ello la narrativa como escenario de interpretación hermenéutica se convierte en el pilar fundamental para lograrlo. En la fundamentación, discusión de la interpretación y la comprensión se discurrirá en varias nociones conceptuales aportadas por autores como Paul Ricoeur y otros, que le permiten quien lee reconocer cómo la hermenéutica y las narrativas son espacios propicios de investigación de las ciencias humanas que permiten interpretar y re-significar la vida de los individuos.

Palabras clave: Narrativa; Hermenéutica; Interpretación; Comprensión.

\begin{abstract}
In society, there are different population groups in vulnerable spaces or living conditions, which are invisible and excluded from it due to social prejudices. Therefore, the need consists in regaining the denied voice, empowering from their capacity of expression as well as re-signifying their own reality and the nearest reality that surrounds them. In the need for resignification human experience, it is necessary that beyond identifying or describing the ways of life of each individual, it can be themselves who in a lively voice, and with help from Academy, show us the world their humanity. As a result, interpretation and understanding of their being-in-the-world is the objective of the present research, where the narrative as a stage of hermeneutic interpretation becomes the fundamental pillar to achieve it. In the fundamental discussion of interpretation and comprehension will be run in several concepts contributed by authors such as Paul Ricoeur and others, which allow us to recognize how hermeneutics and narratives are propitious spaces for researching in human sciences because they allow to interpret and resignify individual lives.
\end{abstract}

Keywords: Narrative; Hermeneutics; Interpretation; Comprehension.

\footnotetext{
${ }^{1}$ Licenciado en Filosofía y Educación Religiosa, Magister en Educación, Candidato a Doctor en Educación por la Universidad Católica de Córdoba. Docente Investigador de la Universidad Santo Tomás. Investigador del Instituto de la Haya para la Paz, los Derechos Humanos y la Justicia Penal Internacional. Miembro de la red teológica Amerindia. profesorjohannieto@gmail.com o johannieto@ustadistancia.edu.co. ORCID: https://orcid.org/0000-0002-8608-8511

${ }^{2}$ Licenciado en Filosofía, pensamiento político y económico. Auxiliar de procesos investigativos, docente de educación básica y media. Coordinador de procesos de acreditación de calidad. marioangarita@ustadistancia.edu.co. ORCID: https://orcid.org/0000-0002-2876-6054

${ }^{3}$ Licenciado en Filosofía, pensamiento político y económico. Auxiliar de procesos investigativos, docente y líder social en escenario de construcción de paz y pastoral educativa. juanmunoz@ustadistancia.edu.co. ORCID: https://orcid.org/0000-0001-6620-4004

${ }^{4}$ Filósofo, profesor universitario e investigador en el área de la Filosofía de la Educación, en la Universidad Santo Tomás. Candidato a Doctor en Educación por la Universidad
} Católica de Córdoba en Argentina. gustavolabrador@ustadistancia.edu.co. ORCID: https://orcid.org/0000-0002-3717-1407 


\section{Introducción}

En el ámbito académico, la investigación narrativa se ha labrado un lugar importante dentro de la investigación en Ciencias Sociales y Humanas, donde ha abierto su camino en la esfera de la investigación científica de carácter social; es en este espacio académico donde encuentran cabida las reflexiones del presente texto. Para autores como García y Munita (2016) la investigación narrativa tiene su origen en la necesidad de reconocer las diversas formas de comprender y describir el actuar de los grupos humanos, ya que nos pone en contacto con la especial manera en que se relatan las situaciones $\mathrm{y}$ cómo estas son comprendidas y re-significadas. Así pues, la investigación de carácter narrativo se presenta como una nueva exploración social, la cual, custodiada por el llamado "giro narrativo", vivido en la década de los setenta del siglo XX, ve la necesidad de "recuperar relatos olvidados y explorar diversas formas de escritura, que respondieran a la crisis de los grandes relatos hegemónicos" (García y Munita, 2016, p. 159). La narrativa se desarrolla como una forma de producción de discursos reflexivos y empíricos que se apartan del objetivo de promover códigos universales, con el fin de aproximarse a la realidad concreta, determinada, habitual y propia de cada sujeto.

La investigación de carácter narrativo parte de las experiencias y acontecimientos vividos desde las voces y sentires de sus protagonistas, lo que permite tener cercanía a sus comportamientos, motivaciones e interacciones, como elementos característicos y complejos que, al constituirle, reconocen que "la historia narrada es siempre más que la simple enumeración, en un orden seriado o sucesivo, de incidentes o acontecimientos, porque la narración los organiza en un todo inteligible"
(Ricoeur, 2006, p. 10-11), de allí su aporte a la construcción de un conocimiento científico y estructurado. Para Blanco (2011), la narrativa es una "propuesta de considerar nuevas formas de llevar a cabo investigación social, entre otras, concebir a la escritura como un método de investigación y no meramente como una forma final de presentación de resultados" (p. 137), en cuanto reconoce como principio la participación de los sujetos de investigación en la construcción del sentido existencial, experiencial y cognitivo que se conecta con la propia historia y la realidad contextual del territorio en donde se desarrolla.

Ahora bien, para dar peso y valor a la narración como método de investigación, el presente artículo abordará en primer lugar el tema de la hermenéutica como lugar epistémico de la investigación narrativa, pues "una acción deja una huella, pone su marca, cuando contribuye a la aparición de pautas que se convierten en los documentos de la acción humana" (Ricoeur, 2002, p. 179). Picontó Novales (2005) afirma que, a criterio de Ricoeur, la inquietud más importante de la hermenéutica es presentar un mundo frente al texto, para él, el conocimiento propio de sí mismo lleva al sujeto a dejarse cuestionar por lo que se llama "la cosa del texto", que en este caso serán las narraciones de las experiencias de vida. Es en esta dinámica, Ricoeur (1975) da al texto un carácter liberador en una doble vía: el texto como cosa limitada de valor normativo en su encuentro con el lector, y por otro lado la comprensión crítica a la que llega el intérprete.

En segundo lugar, se pretende dar validez a la investigación narrativa dentro de la investigación cualitativa, ya que "los mismos especialistas aceptan que la investigación narrativa comparte una serie de características con otras formas o estilos de hacer investigación del enfoque 
cualitativo, entre los más conocidos están los que se identifican como autobiografía y relatos de vida" (Blanco, 2011, p. 140), es por ello que los investigadores cualitativos se valen de un gran número de procesos hermenéuticos para hacer comprensibles las experiencias de vida narradas y estudiadas, (Denzin y Lincoln, 2012) ya que la sociedad está constituida por individuos con sentires y pensares diferentes del mundo y de sus realidades, los cuales estamos llamados a estudiar y comprender.

Finalmente se abordarán las características de la narrativa y la relevancia de esta en el contexto actual, para ello se parte de la premisa que la narrativa "es una particular reconstrucción de la experiencia (del plano de la acción al sintagmático del lenguaje), por la que -mediante un proceso reflexivo- se da significado a lo sucedido o vivido" (Bolívar, Domingo, y Fernández, 2001, p. 20), llevándonos a reconocer que la construcción de relatos es parte de la interpretación que seres humanos hacen de su experiencia y la de los otros, otorgando sentido a su mundo.

\section{Hermenéutica como lugar epistémico de la investigación}

La manera en la que es comprendida y transmitida la historia de la humanidad ha cambiado con el transcurrir del tiempo. En un primer momento, se hizo bajo los criterios de la tradición oral y luego para ser más fieles al contenido propio se encontró en la escritura una manera de salvaguardar la esencia de las narraciones de los pueblos. Sobre la escritura se pueden tejer cantidad de cuestiones acerca de su propósito, sintaxis, texto, entre otros elementos propios. Sin embargo, y como se enunció antes, se desarrollará una descripción acerca de la interpretación que se hace de la escritura, y en este caso en concreto del texto como discurso fijado por la misma (Ricoeur, 2002). Para Ricoeur (1984) el texto tiene una doble dinámica o tarea: Ad Intra, que conduce la estructura de la obra y Ad extra, que la proyecta fuera de sí misma, engendrando un mundo que será la "cosa" del texto. Por tanto, la tarea de la hermenéutica es la de reconstruir la doble función del texto (Villaverde, 2006).

Ricoeur (2001) hace una contraposición entre la lengua y el discurso: la primera es definida como un conjunto de signos, la cual es atemporal y virtual; el discurso por su parte lo define como un "acontecimiento del habla", por lo tanto, tiene dimensión temporal, que se actualiza en cada momento y está dispuesto a un sujeto que lo pronuncia y a un interlocutor que lo recibe. De este modo, el discurso tiene en sí un poder que se trasmite hacía el exterior y que trasciende per se al quedar expuesto a la comprensión. Lo anterior lo constituye en una objetivación que culmina en el distanciamiento con la fijación aportada por la escritura - tradición oral (Wicks, 2005).

En el discurso escrito no hay intercambio directo entre sujeto escritor y lector, pese a que exista una relación de conocimiento implicitica; por ende, la coherencia entre la intención y la significación pueden distanciarse y reemplazarse por un significado indeterminado y solo correspondiente a las características en las que se dé la lectura y la escritura. Sin embargo, el texto escrito permite que la narración sea un lugar de encuentro entre sujetos separados por el tiempo y el lugar, y que entre ellos se desarrolle una relación de sentido dependiente de las intenciones sujetas al ejercicio de interpretación. De este modo, el texto dice a otro algo acerca de lo que es dicho y cómo es dicho, siendo referente del discurso. De este modo, allí se encuentran quien dice (escritor), lo dicho y la forma en la que esto es dicho (referente) 
y a quien se ha dicho (lector). Dicha relación entre temporalidad, intención, destinatario original y mundo circundante, genera un espacio intersubjetivo en el que la interpretación articula el tiempo de lo escrito con el tiempo de lo leído; comprometiendo la verdad de la escritura como posibilidad hermenéutica. Con ello se hace objetivo el distanciamiento propiamente dicho y las características del texto (Wicks, 2005).

El concepto de texto no se agota en el discurso escrito (Ricoeur, 1984); por tanto, al no haber una referencia ostensiva y al autor no determinar el significado del mismo, se debe interpretar la proposición de mundo hecha por el texto, es decir la posibilidad de ser-en-elmundo (Wicks, 2005). El fin último del texto es la mediación de la auto compresión, donde el lector contextualiza la realidad y profundiza en la comprensión de sí en la búsqueda de nuevas formas de ser en el mundo. Debe apropiarse del texto para descubrir su propuesta y desapropiarse para hacer una crítica objetiva de auto compresión para seren-el-mundo (Wicks, 2005).

Paul Ricoeur, al abordar la discusión sobre la propuesta del texto y la autorreflexión del lector para ser en el mundo, por medio de la exploración e interpretación del mismo, sintetiza la cuestión identificando las siguientes características (Londoño, 2007):

1. El texto narrativo ofrece al lector un mundo donde puede habitar, apropiándose del texto y por ende de su ser-en-el-mundo. 2. El lector es quien hace posible la referencia al mundo del texto en el contexto real, suponiendo una crítica objetiva de la realidad o irrealidad en la historia, o construyendo su propia realidad a partir de lo que lee.

3. La hermenéutica permite interpretar la realidad del texto con todos los mundos posibles, el cual ya ha sido interpretado, pero que permite y exige necesariamente una interpretación y comprensión de sí mismo y de su realidad respecto al texto.

La propuesta Ricoeuriana descarta la idea de un sujeto auto-fundante, pues la noción de símismo no puede equipararse con la del cogito ${ }^{5}$ y por el contrario supone que toda comprensión de sí debe acrisolarse por los textos y por la consideración de la alteridad como constitutiva de la identidad personal. (Londoño, 2007). Ricoeur en el ser-en-el-mundo conjura la primacía de la subjetividad afirmando que, "en la medida que el sentido de un texto se automatiza de la intención subjetiva de su autor, el problema esencial no consiste en encontrar, detrás del texto, la intención perdida, sino en desplegar, ante el texto el mundo que abre y descubre" (Ricoeur, 2002). El objetivo es extraer el fundamento interpretativo del escenario de la conciencia en relación consigo misma al contexto de mundo abierto por los textos. De este modo, la subjetividad pasa de ser el origen de la interpretación, a ser el punto de llegada del mismo. (Londoño, 2007). La hermenéutica tiene una función crítica respecto de la sociedad, no solamente es interpelarse respecto del texto y del ser-en-el-mundo de la persona consigo misma, sino de serlo en relación con el contexto circundante. Lo anterior, supone entonces que la hermenéutica debe lograr una interpretación

\footnotetext{
${ }^{5}$ En Descartes, el cogito se presenta como la forma de volver al sí mismo y reconocer la existencia objetiva del ser-en-elmundo. De ahí su máxima cogito ergo sum.
} 
de la sociedad, posibilitando la comprensión y transformación (Romero, 1981).

Habermas (citado en Romero, 1981) plantea que las ciencias sociales y humanas deben ser diariamente interpeladas e interpretadas, pues la realidad circundante de un modo u otro les da sentido o significación. Para Gadamer (1977) la realidad social es un paradigma desarrollado continuamente sobre las relaciones sociales y sus dimensiones, generando un hito de interpretación y comprensión humana que se desenvuelve dentro de un contexto-límite históricamente preciso que no se debe perder de vista; esto hace que se genere claramente una crítica de ideologías, un análisis de sistemas sociales y la realización de una filosofía de la historia como ejes fundamentales para entender y comprender el mundo (Romero, 1981).

La comprensión del mundo y de la realidad social, desde una perspectiva Ricoeuriana, debe ser investigada y profundizada en un proceso interpretativo conexo a la comprensión existencial en la explicación científica. Dicho proceso interpretativo, y la articulación de la comprensión existencial (comprender) de Heidegger, así como de Gadamer (1977), junto al análisis del carácter metodológico/científico (explicar) reivindicado por Habermas (citado en Romero, 1981), se sintetizan en la verdad y el método (Gadamer, 1977), los cuales están ligados dialécticamente. Ricoeur (1984) considera que, si la explicación es el itinerario de la comprensión, el método y la verdad no son polarizantes sino instrumentos constitutivos del proceso dialectico (Novales, 2005). Para desarrollar estos elementos, Ricoeur (1984) profundiza en el análisis del texto, el conocimiento histórico y la teoría de la acción social.En este sentido, esta investigación se presenta como punto de partida en la resignificación del seren-el-mundo de quienes de un modo $\mathrm{u}$ otro han sido anulados e invisibilizados por la sociedad. La interpretación y comprensión del mismo, a través de la narrativa como un escenario de investigación y configuración social de la hermenéutica, es pues preponderante ya que permite al lector realizar una lectura holística y sobre la base de la alteridad de las realidades de los menos favorecidos.

\section{Las narrativas y su lugar dentro de la investigación cualitativa}

$\mathrm{Al}$ abordar el enfoque de la investigación narrativa, es necesario ubicarla dentro de la investigación cualitativa, con sus métodos sistemáticos, calificadores y de recolección de la información que son aplicados al estudio de un fenómeno o problema expresado y comprendido a través de las narrativas, cuyas generalidades reposan en la fenomenología, el constructivismo, el naturalismo y la hermenéutica. Al identificar el punto de partida de la investigación cualitativa, es conveniente recordar que encuentra su origen en la realidad y los fenómenos sociales, los cuales deben ser estudiados e interpretados, con el propósito de hallar sentido a los mismos; por tanto el proceso de recolección de los datos dentro de este tipo de investigación busca proporcionar la mayor comprensión de los significados y experiencias de los individuos o comunidades sujeto de estudio, y por consiguiente "la investigación cualitativa se enfoca en comprender los fenómenos, explorándolos desde la perspectiva de los participantes en un ambiente natural y en relación con su contexto" (Hernández Sampieri, Fernández Collado, y Baptista, 2014, p. 358).

La investigación cualitativa se caracteriza por asumir el enfoque inductivo, lo cual lleva al investigador a conocer el terreno en el que se está insertando, por ello Denzin y Lincoln (2012) 
afirman que "la investigación cualitativa es una actividad situada, que ubica al observador en el mundo" (p. 48), desarrollando un conjunto de prácticas materiales y exegéticas que hacen perceptible el mundo y lo innovan a través de diversas técnicas de recolección de datos. De esta manera, la elección de los procesos de investigación obedecen a las problemáticas que se hayan expresado y están sometidas a unas situaciones espacio temporales determinadas, que permiten a esta metodología asumir una orientación interpretativa y científica del mundo, propiciando que cada investigador realice sus estudios inmerso en los contextos y realidades, con la intención de comprender e interpretar los fenómenos, partiendo del valor y significado que le dan sus protagonistas y su entorno. Entonces, la investigación cualitativa emplea diversos métodos con el ánimo de asegurar el juicio del fenómeno en cuestión, desplegando una atmósfera de acciones interpretativas, en la cual no se prioriza una sola metodología de investigación, puesto que "tiende a ser flexible en su metodología. La forma específica de recolección de información se va definiendo y transformando durante el transcurso de la investigación, dadas las condiciones naturales en las que se realiza” (Martínez, 2011, p. 14).

Empleandodiversosrecursos, esteparadigma investigativo procura que cada método o práctica contribuya al conocimiento de manera sistemática y complementaria, por lo cual "la investigación cualitativa constituye un campo interdisciplinario, transdisciplinario, y a veces contradisciplinario, que entrecruza las humanidades con las ciencias sociales y físicas" (Denzin y Lincoln, 2012, p
56), donde existe un compromiso con la visión científica y con la comprensión exegética de las experiencias de los individuos, sus comunidades y sus vivencias, donde cada investigación es diferente la una de la otra, al no contar con procedimientos estandarizados.

En coherencia con lo anterior, investigar desde un enfoque cualitativo es asumir un compromiso con la sociedad, ya que a través de sus preguntas y las respuestas obtenidas a las mismas, permite que la experiencia humana, que es a su vez una experiencia comunitaria, sea dotada de sentido y valor, la cual busca contribuir a la construcción social, ya que encuentra sus problemas de estudio en la misma sociedad, pues "la sociedad la conforman seres humanos que sienten y piensan, y sus interpretaciones del mundo deben ser estudiadas" (Denzin y Lincoln, 2012, p. 67); por tanto, su tarea es la de realizar una observación objetiva de las experiencias e interacciones humanas, donde el investigador tiene la responsabilidad de ocupar un papel activo frente a las mismas, pero en el que este recibe una mirada individual del "otro" como sujeto observado, en palabras de los autores: "no existen, pues observaciones objetivas, sino sólo observaciones situadas socialmente en (y entre) los mundos del sujeto observador y el observado" (Denzin y Lincoln, 2012, p. 83), pues todo depende de la mirada y el filtro ${ }^{6}$ con el que se realice dicha observación.

Para generar una construcción de conocimiento desde la investigación cualitativa es necesario conocer su base epistémica. Al

\footnotetext{
${ }^{6}$ El sujeto determina la realidad desde el filtro que le proporciona el mundo de la vida. Es decir que solo se ve lo que se sabe. La construcción de los filtros con los que se interpretan la realidad dependen de las relaciones que el sujeto tiene con la realidad inmediata y por ende, en la narración, la lectura de quien escribe y quien lee se fusionan en un espacio intersubjetivo de interpretación.
} 
respecto, se puede afirmar que está "fundada en una posición filosófica que es ampliamente interpretativa en el sentido que se interesa en las formas en el que el mundo social es interpretado, comprendido, experimentado y producido" (Vasilachis et. al 2006, p. 25). Por ello, la principal característica de este tipo de investigación reside en el aporte del significado y la interpretación, teniendo como punto de partida los contextos de los actores sociales.

En este sentido, Vasilachis et. al (2006) afirman que son rasgos característicos de la investigación cualitativa: la conciliación de las metodologías y las hipótesis; el punto de vista de los protagonistas y su diversidad (puesto que cada uno puede tener una mirada propia del mismo fenómeno); y la capacidad reflexiva del investigador y de la investigación, ya que la interacción entre el investigador y los actores sociales (de sus sentires y pensares) hace parte del proceso de comprensión, interpretación y encuentro de sentido de la experiencia observada. Por lo tanto, "los métodos cualitativos, como un tipo de investigación, constituyen un modo particular de acercamiento a la indagación: una forma de ver y de conceptualizar, una cosmovisión unida a una perspectiva teórica para comunicar e interpretar la realidad" (Vasilachis et. al, 2006, p. 27), de tal manera que frente a las realidades estudiadas se presenta el reto de particularizar y reconocer lo que es distintivo de cada situación, alejándose de las comparaciones que no aportan nada al interés científico de la misma.

El enfoque cualitativo en investigación identifica en los datos construidos y recogidos por investigadores, la fuente primaria que valida el proceso de investigación, por lo tanto, "los métodos de investigación, los datos y el análisis de estos deben mostrar, las formas de la cultura y de la acción social que se desea investigar" (Atkinson como se citó en Vasilachis et. al, 2006, pp. 2930); en tal medida la diversidad de las técnicas y de los testimonios deben ser coherentes con las diferentes características del contexto social que se está estudiando, los cuales conducen a hipótesis y resultados. Dicha interpretación se hace valiéndose de diversas metodologías, así la observación de carácter cualitativo "es un nuevo momento del trabajo de campo en el que el analista debe observar su propio proceso, al mismo tiempo que realiza el análisis y dar cuenta de él conjuntamente con el informe de los resultados de la investigación" (Vasilachis et. al, 2006, p. 30).

El modelo cualitativo se preocupa de la vida de los individuos, de sus tradiciones, de sus conductas y de sus interacciones, de su vida comunitaria; por eso la interpretación de las narrativas como una manera de representación de la vida no se considera de forma individual, sino como parte de un todo social, los cuales representan el quehacer de una comunidad dotada de pleno sentido, y que requiere ser estudiada y comprendida. En ese orden, el propósito de recurrir a la investigación con enfoque cualitativo es entender el valor que los actores sociales dan a su existencia, al igual que dar razón de sus contextos y la influencia de los mismos, reconocer posibles situaciones de investigación y dar respuesta a los cuestionamientos identificados. Como consecuencia de esto, "los resultados de la investigación cualitativa inspiran y guían a la práctica, dictan intervenciones y producen políticas sociales" (Vasilachis et. al, 2006, p. 31), por ello se afirma que la investigación cualitativa requiere de una gran sensibilidad y compromiso sociopolítico.

Denzin y Lincoln (2012) hacen una división de la historia de la investigación cualitativa en ocho 
etapas o momento. Algo claro para sus detractores es que esta división la realizan solo a partir del ámbito anglosajón, ya que en los países de habla hispana se ha vivido otro proceso, donde el diseño metodológico de investigación cualitativa hace una clara resistencia a ser calificada desde unos criterios que le son ajenos al espacio sociocultural en el que se suscribe. Sin embargo, cabe anotar que a nivel de referencias bibliográficas frente a la investigación cualitativa, la propuesta de Denzin y Lincoln (1994) propone que "los comentarios y críticas que suscita ponen en evidencia la diversidad de tendencias, escuelas, concepciones y perspectivas presentes en nuestros días en la investigación cualitativa" (Vasilachis de Gialdino, y otros, 2006, p. 38).

Finalmente, cabe anotar que las dinámicas más recientes de investigación cualitativa no necesariamente siguen el patrón clásico del investigar, a saber, el de la deliberación metódica y filosófica; sino que, por el contrario, lo van desarrollando y enriqueciendo a lo largo del ejercicio de investigación. Frente al argumento epistemológico dentro del enfoque cualitativo, cabe recordar que todo investigador emprende su tesis desde un paradigma o supuesto, que considera el aspecto ontológico (la realidad y su naturaleza), epistemológico (el lugar del conocimiento), axiológico (los valores y la ética de la investigación) y metodológico (el paso a paso de la investigación). La investigación cualitativa, desde su lugar epistémico, busca cuestionar la manera como la realidad puede ser construida, la correlación con quien la produce y el alcance de consecuencias. Actualmente, desde la investigación cualitativa y sus reflexiones epistemológicas, se presenta la coincidencia frente a lo ontológico, lo epistemológico y lo metodológico de tres paradigmas: el materialistahistórico, el positivista y el interpretativo. En múltiples investigaciones observamos la manera en que dichos paradigmas contribuyen al desarrollo y resultados de las mismas, puesto que estos hacen parte de lo que se podría llamar "la epistemología del sujeto cognoscente", quien es el sujeto ubicado en un contexto especifico, el cual a partir de su postulado epistémico y procedimental desarrolla la investigación, llevándole al encuentro del "sujeto conocido".

\section{La narrativa, una apuesta en la investigación y cimentación del conocimiento}

El paradigma hermenéutico desde el cual se sitúa la presente comprensión de la narrativa "adopta una ontología relativista, una epistemología transaccional y una metodología hermenéutica dialéctica" (Lincoln y Guba, 2012, p. 29). La narrativa se presenta como una forma de estudiar y comprender la manera como los individuos captan su realidad, buscando "recobrar el sujeto en la investigación, el tiempo de relación y la reflexión en un compromiso con la persona, con el modo de relacionarnos, con el cuidado en el proceso, recuperando "el sujeto" como investigador o investigadora y como partícipe" (Rendon Pantoja y Angulo Rasco, 2017, p. 134); en una sociedad donde los grandes discursos han perdido valor y relevancia, "hemos abocado a refugiarnos en las pequeñas, pero auténticas, narrativas personales, que tienen un potencial para representar la experiencia vivida" (Bolívar y Porta, 2010, p. 203).

En un mundo que se muestra global, donde los individuos son considerados ya no ciudadanos de un país, sino del mundo, los sujetos abrigan una necesidad fundamental de relatar sus referentes de identidad, donde encuentran como lugar seguro el abrigo en el propio yo. Así, la narrativa se presenta como un instrumento que permite incorporarse 
al orbe de la identidad y de las personas desde su cotidianidad. Para Porta y Flores (2017) la narrativa hace del narrador un prota $\neg$ gonista de la acción relatada, como actor o como observador preocupado, el cual se muestra cuestionado por el quehacer de los demás y por el juicio narrativo que reconoce en la singularidad de cada situación.

En consecuencia, la narrativa, desde el contexto hermenéutico, da significado y advierte las dimensiones epistemológicas, afectivas y de interacción de los sujetos: por lo tanto, narrar las vivencias personales e interpretar dichas situaciones, desde la mirada de quienes las viven, propicia un giro epistemológico en el proceso investigativo que consiste en el reconocimiento de la importancia del carácter discursivo de la singularidad, a la manera como los seres humanos viven y dan valor al contexto y realidad, representándose y expresándose a través de sus historias. Esas singularidades potencian diversas subjetividades, convirtiéndose en un elemento indispensable para comprender la sociedad. En este punto es relevante reconocer que la narrativa tiene un campo de acción dentro de la investigación de carácter hermenéutico cualitativo (Bolívar, Domingo y Fernández, 2001) como resultado del fenómeno que se investiga, el cual proporciona un escenario para edificar y examinar los fenómenos representativos, y un método de investigación capaz de generar, mediante la reflexión, modificaciones en las prácticas frente a la realidad estudiada.

Ahora, la narrativa tiene la característica constitutiva de la experiencia observada como relato vital, el cual se caracteriza por estar motivado por el investigador y recogido desde la voz exacta de la entrevista al sujeto, sin recibir un complemento de otras fuentes (Vázquez, 2005); y también como historia de vida la cual necesita de la "consulta de otras fuentes además de la entrevista, tales como cartas, diarios (...) y la consideración de elementos más complejos como el tiempo, con el fin de reconstruir el acontecer completo o parcial de la vida" (Vázquez, 2005, p. 58). En consecuencia, trae consigo una estructura como método de recopilación de experiencias, pues, "esta es una forma de construir realidad, de ordenar la experiencia, apropiarse de ella y de sus significados particulares y colectivos" (Bolívar y Porta, 2010, p. 204). Desde el ámbito hermenéutico, se toma como referente filosófico a Paul Ricoeur (2004), quien presenta "una filosofía sobre el sentido del sentido" (p. 9), ya que la hermenéutica no se preocupará por lograr la afinidad de la subjetividad del autor con la subjetividad del interprete, sino que su interés será alcanzar un encuentro entre el discurso del texto y del intérprete. Se retoma esta idea porque el objetivo de este último apartado es el de reconocer el qué y el cómo de la narrativa dentro del proceso investigativo.

Es a través de los relatos que los individuos examinan y desentrañan su experiencia de vida. Por tanto, "las estructuras narrativas, en efecto, constituyen el marco por el que los humanos dotan de sentido a su mundo" (Bolívar, Domingo, y Fernández, 2001, p. 21), pues proporciona formas de exégesis, interpretación y metas para la acción que contribuyen a la construcción de significados a nivel social e individual. Frente al cómo de la investigación narrativa, Antonio Bolívar (2001) afirma que la trama argumental establece el relato narrativo, pues una narrativa es una cadena de sucesos, cuyo significado comparece por su lugar en la distribución total de la trama. Lo importante es reconocer la manera como los individuos hacen memoria de sus experiencias y las relatan, ya que esto ayuda a la reconstrucción de los significados. Ahora bien, "el tiempo se hace tiempo humano en la 
medida en que se articula en un modo narrativo, $y$ la narración alcanza su plena significación cuando se convierte en una concisión de la existencia temporal" (Ricoeur, 2004, p. 39). Este elemento de temporalidad en la crónica, es lo que permite al investigador dotar de coherencia las experiencias compartidas.

La investigación narrativa no se puede limitar a la mera recolección y análisis de datos, ya que actualmente se cuenta con una estructura epistemológica y metodológica que lleva a ser generadora de conocimiento con validez objetiva y necesarios para la comprensión de los fenómenos sociales; para Paul Ricoeur, la existencia busca percibir cómo un discurso escrito o verbal, entendido como un relato de vida, debe ser leído o escuchado por lo tanto comprendido y dotado de sentido. Por lo general, una investigación de carácter narrativo empieza con la recolección de relatos auto-biográficos, a través de un diálogo que busca intencionalmente abarcar dimensiones de la persona a criterio del investigador; dicho relato es analizado partiendo de unos juicios, para luego dar significado al mismo. En virtud de lo anterior, se debe decir, "que los humanos, son organismos que, individual y socialmente, generan historias vividas; por lo que el estudio de la narrativa es el análisis de los modos como los humanos viven su mundo" (Bolívar, Domingo, y Fernández, 2001, p. 27).

La narrativa habla de la dimensión sensible de la experiencia, de las interacciones, lo dificultoso de estas y la particularidad de las situaciones de individuos. Como carácter de discernimiento, la narrativa reconoce el valor y pormenores de los significados, sus implicaciones en las experiencias de estos (sentires, pensares, motivaciones, sueños), que en la mayoría de los casos no logran ser comunicados en definiciones y expresiones reales, entendibles, como sucede en el razonamiento lógico-formal. Es allí donde el experimento de hacer una definición científica de los comportamientos e interacciones humanas, ha motivado la necesidad de comprender los acontecimientos sociales como discurso, en los cuales los mismos protagonistas, a partir de un ejercicio personal de comprensión, le dotan de significado y sentido a nivel hermenéutico. Lo anterior, ratifica que una hermenéutica narrativa reconoce la comprensión de los laberintos psicológicos de las narraciones que las personas conciben de los problemas y las disyuntivas de la vida (Bolívar, Domingo, y Fernández, 2001).

Otro aporte de la investigación narrativa es su alcance político y social, ya que "desde sus orígenes en la antropología social e historia oral, la narrativa se ha empleado para investigar personas marginadas por razón de género, clase o raza" (Bolívar, Domingo, y Fernández, 2001, p. 61). Como ya se mencionó, este abordaje tiene un compromiso con la comprensión y construcción de una mejor sociedad, al dar voz a aquellos que les ha sido arrebatada, o que, por sus contextos, sus experiencias no han sido documentadas. No obstante, se debe tener cuidado de llevar la acción de la narrativa solo al plano personal, pues esto desconectaría el componente social y político que le da sentido y significado a la misma, incurriendo en el error advertido por Denzin, (1989) de promover la idea utópica de que entendemos cuando no es así, o que hemos encontrado relatos y narrativas significativas cuando no lo son cayendo en prácticas culturales autoritarias. Es así como Bolívar (2016) lo explica:

En este tiempo, las personas se ven impelidas a construirse sus propias vidas, que ya no vienen dadas por un marco institucional, con la inseguridad o riesgo que genera este continuo 
tomar decisiones propias. Una búsqueda del propio sentido de la vida mediante su "puesta en orden" del relato. De modo paralelo al fin de siècle anterior, la pérdida de fe en el racionalismo ilustrado y en las explicaciones totales del mundo ("grandes narrativas" o "metarelatos"), han abocado a refugiarse en las pequeñas, pero auténticas, narrativas personales (p. 342).

Por esto, se debe aceptar que las historias de vida $^{7}$ son el resultado de la construcción y reconstrucción que el individuo y lo que le rodea hace permanentemente de sí mismo, pues la sociedad está en constante cambio y no le proporciona una base ética, política, social, de la cual pueda asirse como referente de vida, puesto que, "las nuevas formas de saturación social, dan lugar a tantas voces y ecos, que el yo auténtico o identidad personal se esfuma o desmorona, porque un yo plenamente saturado deja de ser un yo" (Bolívar , Domingo, y Fernández, 2001, p. 71), de allí la importancia de hacer una dialéctica de la reconstrucción del yo. Por esto, la investigación narrativa tiene la tarea de identificar la manera de fusionar lo personal, que resulta inseparable de los discursos e historias de vida, con la dimensión política, ya que en ésta última lo personal se despliega y es desde ella que la historia de vida adquiere sentido (Bolívar, 2016).

Para finalizar con este apartado, es importante tener en cuenta que, "la hermenéutica filosófica constituye uno de los principales fundamentos de la investigación narrativa porque este enfoque interpreta vivencias lingüistizadas y pretende alcanzar una comprensión de las experiencias de los sujetos." (Porta y Flores, 2017, p. 683), lo cual permite vínculos con la narración. Como afirma Apel (1985) "todas las corrientes de la filosofía contemporánea convergen desde hace unos decenios en la problemática del sentido, la comprensión y el lenguaje” (p. 265), por esta razón, se presenta una aproximación desde una mirada filosófica, donde se exhiben nuevas clasificaciones de la ideología social como es el enfoque narrativo en la investigación:

[...] un campo de indagación sensible, donde el análisis es ante todo interpretativo, hermenéutico, donde lo que importa es la sutil relación -no equiparable- entre vida, experiencia y palabra, y donde lo emocional, en el profundo sentido de la relación dialógica, es un factor determinante [...] (Arfuch, 2011, p. 190)

La narrativa obtiene un lugar importante a

\footnotetext{
${ }^{7}$ Para pensadores como Denzin (1987) hay una diferencia entre life history y life story, pues la historia de vida reconstruye la narrativa vital de un sujeto recogida por un investigador con todo un entramado de datos adjuntos a nivel familiar, documental, pictórico, entre otros (Martín, 1995)). Mientras que el relato de vida, "se refiere exclusivamente a la reconstrucción biográfica. Es decir, la historia de vida engloba al relato de vida” (Martín,1995, p. 47)
} 
nivel hermenéutico en el marco de la investigación en ciencias sociales, pues dota de significado la experiencia humana. Por tanto, la orientación investigativa narrativa ${ }^{8}$ resiste el problema hermenéutico, desde el inicio de los términos de la exégesis, puesto que, "hay interpretación allí donde existe sentido múltiple, y es en la interpretación que la pluralidad de sentidos se hace manifiesta" (Ricoeur, 1975, p. 17), ya que toda lectura de un discurso constantemente está ligada a una sociedad, cultura o movimiento del conocimiento (Nieto, 2017).

Esto complementa el pensamiento de Mélich (2006), quien concibe al hombre como homo narrans que está en medio de un gran número de historias, causantes de confusión, pues al vivir en la práctica cotidiana de la resistencia, busca el sentido de la vida, por ello:

[...] solamente a través de la narración, del relato siempre dinámico y cambiante de nuestra existencia, cada ser humano puede inventar el sentido de su vida. $Y$ es a través de las narraciones que nos cuentan y que nos contamos como configuramos nuestra identidad, una identidad siempre en devenir, siempre provisional [...] (Mélich, 2006, p. 43)

El valor que la hermenéutica tiene en este contexto, es que instala por sobre todo supuesto genérico e indefinido y sobre toda aspiración, la experiencia auténtica de los individuos, por esto, dentro de las investigaciones narrativas se da un nuevo valor a la subjetividad desde una perspectiva democrática de los saberes pues "estas investigaciones privilegian la voz de los sujetos en su pluralidad, los tonos divergentes y la otredad" (Arfuch, 2005, p. 23), por tanto la narrativa es entendida como una manera de comprender el actuar y el sentir de los sujetos que transforman desde su comprensión, de cuya experiencia emerge un conocimiento, una manera de interpretar la realidad. También contribuye a entender cómo las sociedades se han conformado y comunicado a través la experiencia individual y colectiva, dando identidad a sus integrantes y llevándolos a participar de las significaciones inherentes a la cultura.

A partir de esto, resulta relevante visibilizar la fuerza que adquierela investigación narrativa como una apuesta política y ética (Arias, 2015), en donde el rol de cada investigador y la responsabilidad social frente capital inmaterial del conocimiento "aporta la posibilidad de aproximarse a vivencias sociales desde relatos individuales y también, a la resignificación subjetiva de la realidad a propósito de los cambios de ésta mientras se narra a lo largo del tiempo" (Arias y Alvarado, 2015, p. 178).

\section{Conclusiones}

El estudio de los problemas y fenómenos de los pueblos ha exigido que las investigaciones narrativas cobren un lugar de importancia en el campo de las ciencias sociales. Dichos procesos investigativos deben ir más allá de una descripción de fenómenos y de una explicación sucinta de las realidades humanas; por ende, la fuerza investigativa tiene que irrumpir con mayor amplitud en el campo del análisis, comprensión e interpretación de las mismas. De este modo,

${ }^{8}$ El despliegue del espacio biográfico en la investigación se ve "configurado por innúmeras narrativas en las que el "yo" se enuncia para y por un otro - de las maneras más diversas, también indirectas, elípticas, enmascaradas—, un gesto que pone en forma $-\mathrm{y}$ por ende, en sentido- esa incierta vida que todos llevamos, ese caótico flujo de sensaciones, vivencias, imágenes, palabras y memorias, cuya unidad, como tal, no existe por fuera del relato" (Arfuch, 2016, p. 238). 
y sobre la base de los métodos cualitativos de investigación, emerge la narrativa como horizonte del campo hermenéutico; desde ella se pretende resignificar y visibilizar la realidad de aquellos sujetos que socialmente han sido invisibilizados o anulados; así, la relación entre el ser-en-el-mundo de éstos actores sociales y la interpretación que se da desde la aproximación al discurso escrito permiten que se ahonde holísticamente en la pregunta por la consecución de nuevos conocimientos, cuya finalidad sea develar la manera en que es comprendida la realidad y restituir la palabra de aquellos que no la tienen o les ha sido coartada.

La narrativa desde el campo de la investigación hermenéutica no es tan solo una aproximación subjetiva a la realidad de los actores menos favorecidos o invisibilizados, se trata de un campo de conocimiento que le permite a cada lector sensibilizarse acerca del ser-del-otro, es decir de su alteridad, llevándole a interpretarlo y comprenderlo para actuar en la consecución con los nuevos modos de ser-en-el-otro, un aprendizaje de la alteridad a partir del "reconocimiento de lo humano en medio del "paisaje en ruinas" que ha ocasionado el devastador paso de la razón instrumental" (Nieto y Rodríguez, 2017, p. 94), y con lo cual se explicita un tránsito paradigmático necesario, entre una investigación que "objetivizó" instrumentalmente lo humano, y una investigación que reconoce su subjetividad.

Investigación cualitativa, hermenéutica y narrativa son pues un campo muy amplio de aproximación para la generación de nuevos conocimientos que permitan ahondar en los paradigmas de las ciencias sociales, y aún más, son un escenario de resignificación de ser-en-elmundo de diferentes actores sociales que están ubicados en polos opuestos, quienes a través de la interpretación y comprensión del otro se encuentran, relacionan y construyen nuevas formas de ser-y-hacer-en-el-mundo. 


\section{Referencias bibliográficas}

Apel, K. O. (1985). La transformación de la filosofía. Tomo I. Madrid, España: Taurus.

Arfuch, L. ( 2005). Identidades, sujetos y subjetividades. Buenos Aires, Argentina: Prometeo.

Arfuch, L. (15 de Noviembre de 2011). Reflexiones en torno a la creación del espacio biográfico. Entrevista a Leonor Arfuch. Revista de Educación, 185-192. (M. C. Sarasa, Entrevistador)

Arfuch, L. (2016). Subjetividad, memoria y narrativas: una reflexión teórica y política en el campo de la educación. En Magis. 9(18). pp- 227-244. doi: 10.11144/Javeriana. m9-18.smnr

Arias, . (2015). Conversación sobre la (s) paz(ces): perspectivas y tensiones. En Revista Latinoamericana de Ciencias Sociales, Niñez y Juventud. 13(1). pp. 430-436.

Arias, A. y Alvarado, S. (2015). Investigación narrativa. Apuestas metodológicas para la construcción social de conocimentos científicos. En Revista CES Psicología, 8(2), pp. 171-181

Blanco, M. (2011). Investigación narrativa: una forma de generación de conocimientos. Nueva Época (67), 135-156.

Bolívar , A., \& Porta, L. (2010). La investigación biográfico narrativa en educación: Entrevista a Antonio Bolívar. Revista de Educación, 201-212. Obtenido de http://200.16.240.69/ ojs/index.php/
Bolívar, A., Domingo, J., \& Fernández, M. (2001). La investigación biográfico-narrativa en educación. Enfoque y metodología. Madrid: La Muralla, S.A.

Bolívar, A. (2016). Conjugar lo personal y lo político en la investigación (auto)biográfica: Nuevas dimensiones en la política educacional. Revista Internacional de Estudos e Pesquisas em Educacao Superior, 2(2), 341-365. Obtenido de https://www. fe.unicamp.br/revistas/ged/RIESup

Denzin , N. K. (1989). Interpretative Biography. Newbury Park, CA: Sage.

Denzin, N. K., \& Lincoln, Y. S. (2012). La investigación cualitativa como disciplina y como práctica. En N. K. Denzin, \& Y. S. Lincoln, Manual de investigación cualitativa (Vol. I, págs. 43-100). Barcelona: Gesida, S.A.

Gadamer, H. G. (1977). Verdad y Método. Salamanca, España: Ediciones Sígueme.

García, R., \& Munita, H. (2016). La narrativa como método desencadenante y producción teórica en la investigación cualitativa. EMPIRIA. Revista de Metodología de Ciencias Sociales(34), 155-178.

Hernández Sampieri, R., Fernández Collado, C., \& Baptista Lucio, P. (2014). Metodología de la investigación (6ta ed.). Ciudad de México, México: Mc Graw Hill Education.

Lincoln, Y. y Guba, G. (2012). Controversias paradigmáticas, contradicciones $y$ confluencias emergentes. En Manual de Investigación Cualitativa. Paradigmas $y$ 
perspectivas en disputa Vol. I. (pp 27-78). Barcelona: Gedisa.

Londoño, M. A. (2007). la comprensión de sí en la comprensión de un texto: anotaciones sobre la hermenéutica de Paul Ricoeur. San BuenaventuraUniversity.

Martín García, A. (1995). Fundamentación teórica

y uso de las historias y relatos de vida. En Aula 7 Universidad de Salamanca. pp. 41-60

Martínez Rodríguez, J. (2011). MÉTODOS DE INVESTIGACIÓN CUALITATIVA. SILOGISMO (8), 1-33.

Mélich , J. C. (2006). Transformaciones. Tres ensayos de filosofía de la educación. Buenos Aires: Miño y Dávila.

Nieto, J. A. (2017). Hacia una didáctica del sentido. Didácticas emergentes de las prácticas

pedagógicas de filosofía en tres escuelas católicas. En Revista Interamericana de investigación, educación y pedagogía. 10(1). pp. 173196. DOI: https://doi.org/10.15332/s1657107X.2149

Nieto, J. A. y Rodríguez, J. P. (2017). Del contractualismo igualitario al desarrollo humano diferencial: una perspectiva de justicia desde el enfoque de capacidades humanas en el proceso de retorno a la vida civil de desmovilizados en Colombia. En Revista Hallazgos 14(28). pp. 83-104. DOI: https://doi.org/10.15332/2422409X

Picontó Novales, T. (2005). Hermenéutica, argumentación y justicia en Paul Ricoeur. Madrid, España: DYKINSON, S. L.
Porta, L. G., \& Flores, G. N. (2017). Narratividad e interpretación: nexos entre la investigación narrativa y la hermenéutica. Revista Brasileira de Pesquisa (Auto)Biográfica., 2(6), 683-697.

Rendon Pantoja, S., \& Angulo Rasco, J. F. (2017). Investigación cualitativa en educación. Buenos Aires, Argentina: Miño y Davila Editores.

Ricoeur,P.(1975).Hermenéuticayestructuralismo. Buenos Aires, Argentina: La Aurora.

Ricoeur, P. (1984). Educación y política. Buenos Aires, Argentina: Editorial Docencia.

Ricoeur, P. (2001). Del texto a la acción . Buenos Aires, Argentina: Fondo de cultura económica.

Ricoeur, P. (2002). Del texto a la Acción. Ciudad de México, México: Fondo de Cultura Económica.

Ricoeur, P. (2004). Tiempo y narración I Configuración del tiempo en relato histórico (Quinta ed., Vol. I). México: Siglo XXI Editores.

Ricoeur, P. (2006). La vida: un relato en busca de narrador. ÁGORA, 25(2), 9-22.

Romero, R. M. (1981). Hacia la construcción de una teoría de la interpretación: En torno al debate Habermas-Gadamer. España: Revista Española de Investigaciones Sociológicas . 
Vasilachis de Gialdino, I., Ameigeiras, A. R., Chernobilsky, L. B., Giménez Béliveau, V., Mallimaci, F., Mendizábal , N., ... Soneria,

A. J. (2006). Estrategias de investigación cualitativa (1ra Edición ed.). (E. G. S.A., Ed.) Barcelona.
Villaverde, M. A. (2006). Paul Ricoeur: Los caminos de la hermenéutica. Agora.

Wicks, A. E. (2005). La hermenéutica como camino hacia la comprensión de sí (Vol. 61). Chile: Revista de Filosofía, Universidad de Chile . 